\title{
Numerical Simulation of Inclusion Removal in a Billet Continuous Casting Mold Based on the Partial-cell Technique
}

\author{
Yeong-Ho HO and Weng-Sing HWANG ${ }^{1)}$ \\ Department of Information Management, Diwan College of Management, Tainan, Taiwan. \\ 1) Department of Materials Science and Engineering, National Cheng-Kung University, Tainan, Taiwan.
}

(Received on January 30, 2003; accepted in final form on June 17, 2003)

\begin{abstract}
A mathematical model has been developed to simulate the fluid flow behavior and subsequent inclusion removal rate in a billet continuous casting mold. The model is then used to evaluate the effects of various nozzle designs and operating conditions on the removal of inclusions originally adhere to the continuous casting mold. The ultimate goal is to obtain the optimal design and operating condition to improve the steel cleanliness.

The numerical technique employed in this study is the SOLA-SURF technique incorporated with the partial-cell scheme, which can better approximate the geometry of the simulated system. Other than simulating the flow field of molten steel in the continuous casting mold, the pathlines of nonmetallic inclusions, which are affected by the interactions of inclusion particles and molten steel, are also calculated to directly access the effectiveness of inclusion removal.

The model is then tested on a circular billet continuous caster, which requires the model to have the capability to treat curved surfaces in the geometry of the simulated system. Various port designs in the submerged nozzle and operating conditions such as casting speed and submerged depth of the nozzle are evaluated with the calculated pathlines of the inclusion particles for their effects on the cleanliness of the steel. Results of this research show that the flow pattern in the mold region is affected by the design of the nozzle and operation of the caster. It also shows that submerged depth of the nozzle has a more profound effect on the efficiency of inclusion removal than the casting speed.
\end{abstract}

KEY WORDS: continuous casting mold; SOLA-SURF; partial cell technique; inclusion removal.

\section{Introduction}

In the continuous casting process, most of the defects are formed when solidification starts to occur in the casting mold region. Some of the defects can be improved by subsequent treatments. However, defects such as interior inclusions are very difficult, if not impossible, to remedy. Thus, casting mold is the last region where the billet quality can be improved in the steelmaking process. After this stage, the defects in the billet take shape and can hardly be removed. One of the major defects in the billet is the nonmetallic inclusion trapped in the sub-surface or interior of the billet. These inclusions can cause cracks in the subsequent metal working treatments.

In recent steel refining and continuous casting process, steel cleanliness has been effectively improved in ladle and tundish. However, there are still some residual inclusions flowing into the casting mold through the submerged nozzle. A schematic diagram of the continuous casting process is shown in Fig. 1. Also newly formed inclusions are introduced due to damage of the nozzle and suction of the molten slag/casting powder above the liquid steel. With inclusion lighter than molten steel, part of the inclusions will float gradually to the top and be trapped by the slag layer. However, most of the inclusions flow into the casting mold with the fast flowing melt and are caught and become defects. Therefore, the primary task of improving cleanliness in the casting mold region is to know how these inclusions can be removed before they are caught by the solidified shell in the casting mold.

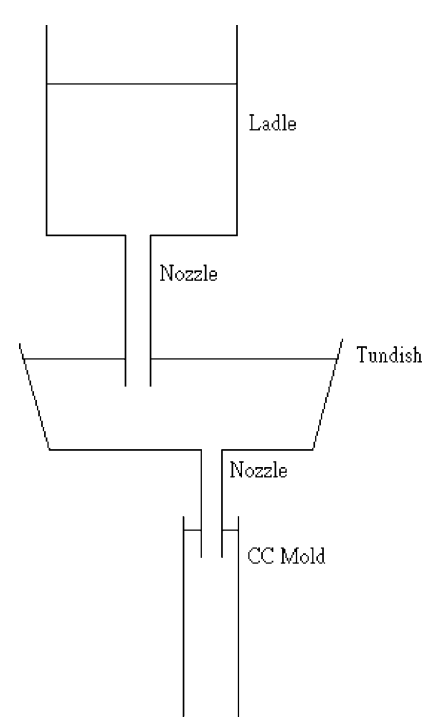

Fig. 1. A schematic diagram of the continuous casting process. 
As described earlier, continuous casting mold is the last area where billet cleanliness can be improved. The type of submerged nozzle and the casting condition can influence the flow behavior of the liquid steel in the casting mold and thus directly affect the floatation of the inclusion in the liquid steel. It in turn determines the quality of the billet. To meet the demands of producing clean steel, it is then essential to find the optimal design and operating condition to improve the cleanliness of the billet.

Basically, there are three ways to reach the goal. One is to do experiments using an actual casting mold-molten steel system. The results are direct and supposedly most accurate. However, due to the opaque nature of the mold and the high temperature operation, such experimentation is very expensive and it is also very difficult to visualize what actually happens. The second approach is to use a physical model, usually a plexiglas-water model. The primary advantage of the plexiglas-water model is that it is relatively easy to observe and measure the liquid flow in the vessel. However, according to the similarity theory, the flow behavior of water is similar to that of molten steel in the mold only if the Reynolds numbers and Froude numbers of both system are equal. Since the kinematic viscosity of water is very close to that of molten steel, the water model has to be of full scale to simulate the flow behavior of the molten steel in the mold meaningfully. A full scale mold is also rather expensive and not very flexible if various designs are to be studied. More importantly, the outlet condition of a continuous casting machine is very difficult to simulate by a plexiglas-water model. The third approach is to use the mathematical modeling technique. ${ }^{1-6)}$ For continuous casting mold study, it first employs a set of partial differential equations and appropriate boundary conditions to mathematically represent the flow phenomena of molten steel in the mold. Then the partial differential equations are formulated, using numerical techniques, into a set of algebraic expressions. Finally a computer program is developed based on these algebraic expressions and boundary conditions. When the program is executed, it is provided with a set of input data which represent the design and operating conditions. The computed results are then interpreted and a great deal of detailed information, such as flow field, variation of the top surface configuration, and pathline of the inclusion can be drawn. Another advantage of the mathematical modeling approach is that it is extremely flexible.

Basically, most of these mathematical models are based on the numerical technique of finite difference method. One major weakness of the finite difference method is its limited capability to treat complex geometry. It usually approximates the complex shape, especially curvilinear and circular shapes, in a zigzag fashion. It significantly reduces the accuracy of the simulations. If the nature of finite difference method is to be retained and the problem of complex shape is to be tackled, an alternative scheme is to employ the partial cell technique. ${ }^{7)}$ In the partial cell technique, a blockage ratio is defined for each of the cell surfaces, which represents the portion of the area of the cell surface blocked by solid obstacles. In this way, curved surfaces can be fitted on a rectangular cell system.

The purpose of this study is to develop a mathematical model that incorporates the 3-D turbulent SOLA-SURF scheme with the partial cell technique to simulate the fluid flow behavior and subsequent inclusion removal rate in a billet continuous casting mold. The model is then used to evaluate the effects of various nozzle designs and operating conditions on the removal of inclusions in the continuous casting mold. The ultimate goal is to obtain the optimal design and operating condition to improve the cleanliness of the billet.

\section{Mathematical Model}

In continuous casting process, the melt enters the watercooled mold from the submerged nozzles of tundish. The primary solid shell is formed by water cooling and the casting powders introduced between the solid shell and the mold for lubrication. At the same time the mold regularly vibrates to allow smooth detachment of the solid shell from the mold. Therefore, the physical phenomena are very complex. To model such complex phenomena, the following simplifications and assumptions are made in this study:

(1) Convection caused by variable temperatures can be ignored.

(2) Existence of solid shell, which is very thin in the mold region, can be ignored.

(3) Inclusions are spherical and can not amalgamate or split up.

(4) Velocity profile at the outlet of the submerged nozzle is uniform.

\subsection{Mathematical Equations}

To simulate the flow behavior of the melt and the movement of inclusions, the following governing equations are used.

\subsubsection{Flow Equations for Liquid Steel}

The flow behavior of the liquid steel is governed by the equations of mass conservation, momentum conservation and turbulence model. The equations are re-formulated based on the partial cell technique. Consider a typical partial cell in the Cartesian coordinate system. The control volume is blocked by a solid region as shown in Fig. 2. Active ratios are defined as the flowable percentages of the partial cell as well as the three faces. For a complete cell, the active ratios are all unity. The governing differential equations can then be described in vector notation as follows.

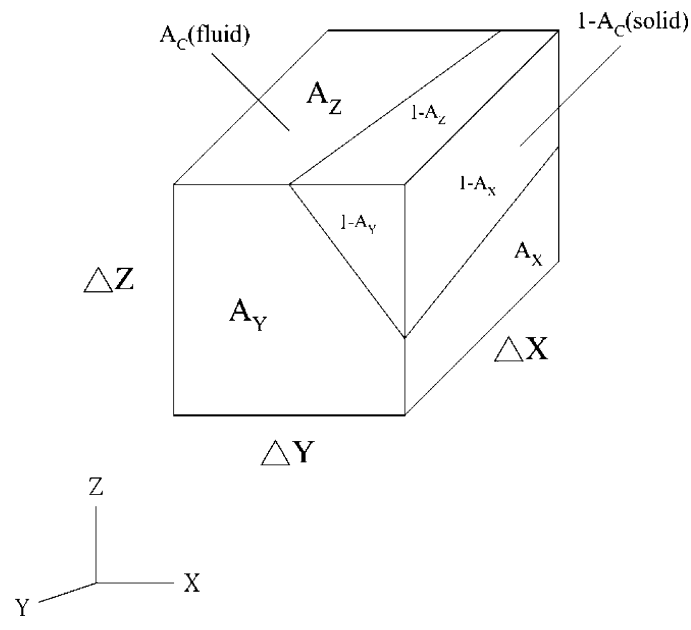

Fig. 2. A typical partial cell blocked by a solid region. 
(1) Continuity Equation

$$
D=\frac{\partial\left(A_{i} U_{i}\right)}{\partial X_{i}}=0
$$

(2) Momentum Equation

$$
\begin{aligned}
& A_{\mathrm{c}} \frac{\partial U_{i}}{\partial t}+U_{j} \frac{\partial\left(A_{j} U_{i}\right)}{\partial X_{j}} \\
& =-\frac{\partial\left(A_{i} P\right)}{\partial \rho_{1} X_{i}}+\frac{\partial}{\partial X_{j}}\left[v_{\mathrm{e}} A_{j}\left(\frac{\partial U_{i}}{\partial X_{j}}+\frac{\partial U_{j}}{\partial X_{i}}\right)\right]+A_{\mathrm{c}} g_{i} \ldots
\end{aligned}
$$

where $U_{\mathrm{j}} \cdot \partial\left(A_{j} U_{i}\right) / \partial X_{j}$ represents the momentum transport due to the convection of fluid, $v_{\mathrm{e}} A_{j}\left(\partial U_{i} / \partial X_{j}+\partial U_{j} / \partial X_{i}\right)$ represents the momentum transport due to viscosity and turbulence .

\section{(3) Turbulence Equation}

The fluid flow in continuous casting mold lies in the arena of turbulent flow and thus the additional momentum transport due to turbulence must be accounted for by a turbulence model. The $K-\varepsilon$ two-equations model is adopted in this study and the governing equations are as follows.

Equation for turbulence kinetic energy, $K$ :

$$
\begin{aligned}
\frac{\partial K}{\partial t}+U_{i} \frac{\partial K}{\partial x_{i}}= & \frac{\partial}{\partial x_{i}}\left(\frac{v_{\mathrm{t}}}{\sigma_{k}} \frac{\partial K}{\partial x_{i}}\right) \\
& +v_{\mathrm{t}} \frac{\partial U_{j}}{\partial x_{i}}\left(\frac{\partial U_{i}}{\partial x_{j}}+\frac{\partial U_{j}}{\partial x_{i}}\right)-\varepsilon
\end{aligned}
$$

Equation for dissipation rate of turbulence kinetic energy, $\varepsilon$ :

$$
\begin{aligned}
\frac{\partial \varepsilon}{\partial t}+U_{i} \frac{\partial \varepsilon}{\partial x_{i}}= & \frac{\partial}{\partial x_{i}}\left(\frac{v_{\mathrm{t}}}{\sigma_{\varepsilon}} \frac{\partial \varepsilon}{\partial x_{i}}\right) \\
& +\frac{C_{1} \varepsilon v_{\mathrm{t}}}{K} \frac{\partial U_{j}}{\partial x_{i}}\left(\frac{\partial U_{i}}{\partial x_{j}}+\frac{\partial U_{j}}{\partial x_{i}}\right)-\frac{C_{2} \varepsilon^{2}}{K}
\end{aligned}
$$

where $v_{\mathrm{t}}=C_{3} K^{2} / \varepsilon$ and the turbulence contants $\left(C_{1}, C_{2}, C_{3}\right.$, $\sigma_{K}, \sigma_{\varepsilon}$ ) are listed in Table 1.

\section{(4) Height Function Equation}

The fluctuation of top free surface may cause the molten slag/casting powder to enter the molten steel. It is then necessary to monitor the fluctuation of the free surface. In SOLA-SURF, a height function method is used to monitor the fluctuation of the top free surface. The governing equation is represented as follows.

$$
\frac{\partial H}{\partial t}+U \frac{\partial H}{\partial X}+W \frac{\partial H}{\partial Z}=V
$$

\subsubsection{Flow Equations for Inclusion Movement}

The movement of the inclusion particle can be expressed as follows.

$$
\begin{aligned}
\frac{d U_{\mathrm{p} i}}{d t}= & -\frac{3}{4} \frac{\mu_{1}}{\rho_{\mathrm{p}} D_{\mathrm{p}}^{2}} C_{\mathrm{d}} \operatorname{Re}\left(U_{\mathrm{p} i}-U_{i}\right) \\
& +\frac{\rho_{1}}{\rho_{\mathrm{p}}} \frac{d U_{i}}{d t}-C_{\mathrm{A}} \frac{\rho_{1}}{\rho_{\mathrm{p}}}\left(\frac{d U_{\mathrm{p} i}}{d t}-\frac{d U_{i}}{d t}\right)+\left(1-\frac{\rho_{1}}{\rho_{\mathrm{p}}}\right) g
\end{aligned}
$$

Table 1. Value of the constants employed in the turbulence model.

\begin{tabular}{|l|l|l|l|l|}
\hline $\mathrm{C}_{1}$ & $\mathrm{C}_{2}$ & $\mathrm{C}_{3}$ & $\sigma_{\mathrm{K}}$ & $\sigma_{\varepsilon}$ \\
\hline 0.09 & 1.44 & 1.92 & 1.0 & 1.3 \\
\hline
\end{tabular}

where $\operatorname{Re}=\rho_{\mathrm{l}} D_{\mathrm{p}}\left|V_{\mathrm{r}}\right| / \mu_{1}$ and the drag coefficient; $C_{\mathrm{d}}$, can be expressed by an empirical formulae. When Re is smaller than $3 \times 10^{5}$, the drag coefficient can be calculated by the following equation. ${ }^{8)}$

$$
C_{d}=\frac{24}{\operatorname{Re}}\left[1+0.15 \operatorname{Re}^{0.687}+\frac{0.42}{\left(1+\frac{4.25 \times 10^{4}}{\mathrm{Re}^{1.16}}\right)}\right] \ldots \ldots \ldots(7)
$$

The movement of the inclusion is affected by three forces. The first term on the right-hand side of Eq. (6) is the drag force that is always opposite to the direction of fluid motion. The second and third terms correspond to the "Added Mass". And the last term is due to gravity. When the velocity of inclusion is known, the pathline of the inclusion can then be drawn.

\subsection{Boundary Conditions}

In addition to the governing equations, it is necessary to set up the boundary conditions. For inlet and outlet of the casting mold, the boundary condition is determined based on the conservation of mass and can be expressed as follows.

$$
V_{\text {inlet }} \times A_{\text {inlet }}=V_{\text {outlet }} \times A_{\text {outlet }}
$$

where $V_{\text {outlet }}$ is equal to the casting speed. For the side walls of the system, the vertical component of the fluid velocity is equal to the withdrawn speed, which is the same as the casting speed.

As for the inclusion particles, boundary conditions are also prescribed at the wall and at the free surface. It is defined that the velocity component of the particle perpendicular to the wall is zero. As the particle reaches the top free surface, the particle is assumed to be absorbed by the top surface layer and thus the velocity of the particle vanishes. After that, the velocity for that particular particle is no longer calculated.

\section{Numerical Scheme}

The numerical method employed in this study is the SOLA scheme in three dimensions. The SOLA scheme is based on the explicit finite difference method. The advantage of this scheme is its low computation time required. It can be easily housed on a personal computer.

\section{Results and Discussion}

A calculated system for particle movement is also developed to estimate the efficiency of inclusion removal. The typical execution time of the program was about $10 \mathrm{~h}$ using a Pentium-III, $667 \mathrm{MHz}$ PC.

The casting mold for a small round billet of $160 \mathrm{~mm}$ in 


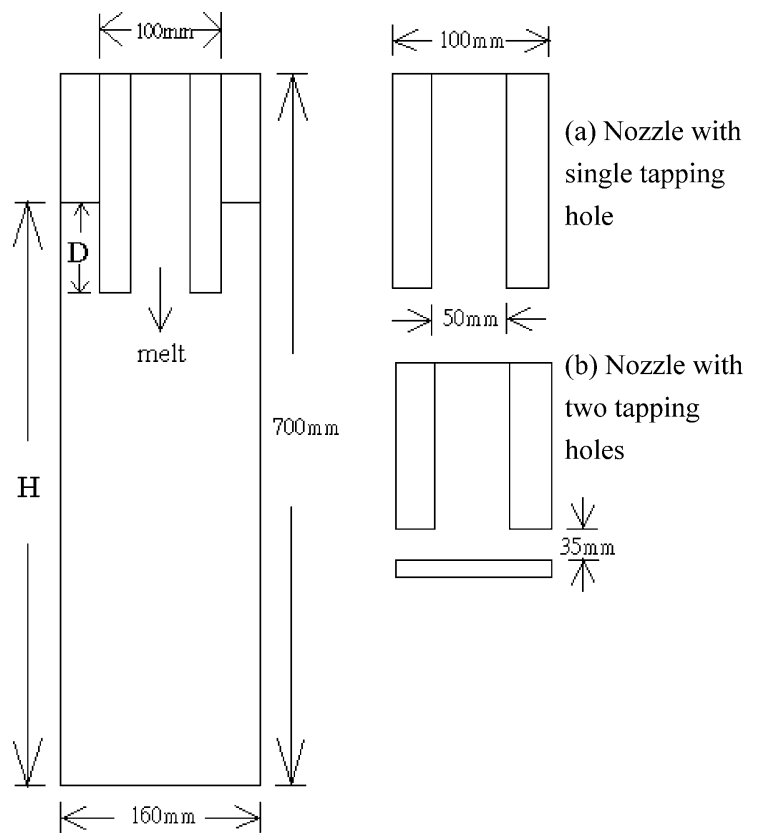

Fig. 3. Schematic diagrams of the billet continuous casting mold and the submerged entry nozzle.

diameter is simulated by the mathematical model developed in this study. Various designs and operating conditions in the continuous casting mold are evaluated for their effectiveness to remove the non-metallic inclusions. Two types of casting nozzle are used. One is $100 \mathrm{~mm}$ in outer diameter and has a downward tapping hole, which is $50 \mathrm{~mm}$ in inner diameter. The other is $100 \mathrm{~mm}$ in outer diameter and has two tapping holes placed horizontally. Furthermore, there are two different submerged depths $(D)$, which are $80 \mathrm{~mm}$ and $100 \mathrm{~mm}$. The submerged depth is defined as the distance between the top free surface and the tapping hole of the nozzle. Also, there are two different withdrawal speeds $(V c)$, which are $1.5 \mathrm{~m} / \mathrm{min}$. and $1.7 \mathrm{~m} / \mathrm{min}$. A schematic diagram of the billet continuous casting mold and the various submerged entry nozzles are shown in Fig. 3. The cross sections of the billet and the nozzle are both circular, which make the application of partial cell technique most appropriate.

The physical properties of molten steel and inclusion as well as the system parameters used in the mathematical model are listed in Table 2. The inclusion velocity at the exit of the nozzle is assumed to be zero rather than the velocity of the molten steel. This assumption means that only the inclusion particles originally adhere to the nozzle wall are considered in this study. The continuous casting mold is divided into a $34 \times 40 \times 34$ mesh system with the appropriate partial cell parameters assigned to each and every cell. The flow field of the liquid steel and pathlines of inclusions for the various designs and operating conditions are then discussed in the following sections.

\subsection{Nozzle with Single Tapping Hole}

In order to demonstrate the differences in the simulated results with and without the incorporation of the partial cell technique, a billet casting mold with the nozzle of single tapping hole, submerged depth of $80 \mathrm{~mm}$ and casting speed of $1.5 \mathrm{~m} / \mathrm{min}$. are shown in Fig. 4. Figure 4(a) is with the
Table 2. The physical properties of molten steel and inclusion and system parameters used in the mathematical model.

\begin{tabular}{|l|l|}
\hline Viscosity of molten steel & $0.0065 \mathrm{~kg} / \mathrm{m} \cdot \mathrm{s}$ \\
\hline Density of molten steel & $7580 \mathrm{~kg} / \mathrm{m}^{3}$ \\
\hline Density of inclusion & $2700 \mathrm{~kg} / \mathrm{m}^{3}$ \\
\hline Drag coefficient $\left(C_{D}\right)$ & 0.44 \\
\hline Mass coefficient $\left(C_{A}\right)$ & 0.5 \\
\hline
\end{tabular}

rectangular mesh system without the incorporation of partial cell technique and Fig. 4(b) is with the partial-cell mesh. The geometry, which employs the partial-cell mesh, is more conformable to the real physical system. The flow patterns look similar. However, by comparing the two flow patterns it can be seen that the velocity near the mold wall by employing the partial-cell technique is more realistic in term of flow direction than that for the rectangular mesh system without the incorporation of partial-cell technique. Moreover, the flare-like high velocity region underneath the nozzle looks deeper with the partial-cell technique than that for the rectangular mesh system without the incorporation of partial-cell technique. Free surface condition is also one of the major concerns in the design and operation in the continuous casting mold. Therefore, the extent of surface fluctuation in this case is simulated. However, it is found to be rather small for both cases with and without the incorporation of partial-cell technique and thus no significant difference is detected. It can be reasoned by the fact that the diameter of the billet continuous casting mold considered in this study is $160 \mathrm{~mm}$ and the outer diameter of the nozzle is $100 \mathrm{~mm}$. The space between the mold and nozzle is rather limited and therefore, the surface fluctuation is small.

Figure 5 shows the velocity fields under two different withdrawal speeds $\left(V_{c}=1.5 \mathrm{~m} / \mathrm{min}\right.$ and $\left.1.7 \mathrm{~m} / \mathrm{min}\right)$ and the submerged depth is fixed at $80 \mathrm{~mm}$. Figs. 5(a) and 5(b) show the flow fields of $X-Z$ and $X-Y$ sections at the withdrawal speed of $1.5 \mathrm{~m} / \mathrm{min}$. while Figs. 5(c) and 5(d) show those at $V c=1.7 \mathrm{~m} / \mathrm{min}$. From these figures, they show that as withdrawal speed increases, the flare-like high velocity region underneath the nozzle becomes larger. The velocity exiting the nozzle opening is larger and the distance of molten steel dashing downward is thus also longer. As the velocity at the outlet of the casting mold is determined by the casting speed, they are also different in these two cases. The velocities on the free surface are not very different and they are large enough to raise concerns as the velocities on the free surface may cause the top surface slag and casting powder to enter the molten steel.

The submerged depth of nozzle is then increased to $100 \mathrm{~mm}$ and two casting speeds $\left(V_{c}=1.5 \mathrm{~m} / \mathrm{min}\right.$ and $1.7 \mathrm{~m} / \mathrm{min}$ ) are investigated. For the sake of comparison, Fig. 5(a) is again shown as Fig. 6(a). The flow fields for the submerged depth of $100 \mathrm{~mm}$ are shown in Figs. 6(b) and 6(c). From the velocity fields shown on the $X-Z$ sections, the velocity near the free surface is significantly reduced as the submerged depth of the nozzle increases.

To evaluate the effectiveness of the design and operating condition, the inclusion removal rate is regarded as a direct criterion. The definition of inclusion removal rate is the ratio of the number of inclusions absorbed by the top slag 

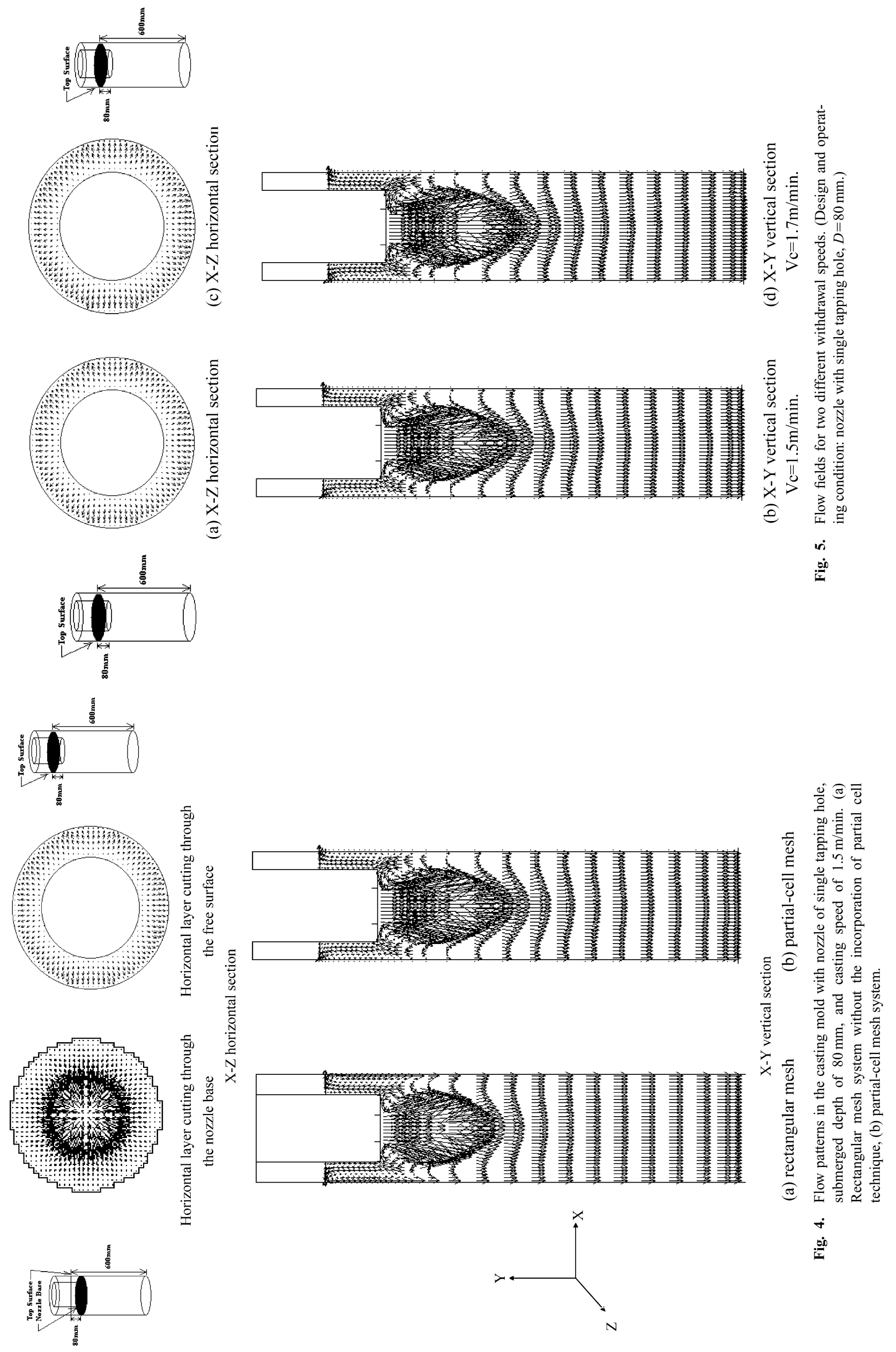

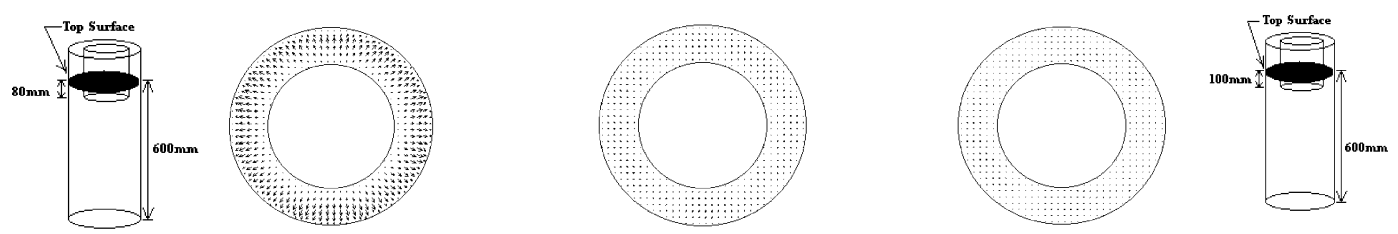

Flow field near the free surface (X-Z section)

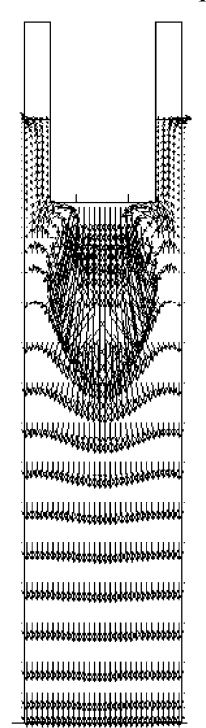

(a) $\mathrm{Vc}=1.5 \mathrm{~m} / \mathrm{min}$. $\mathrm{D}=80 \mathrm{~mm}$

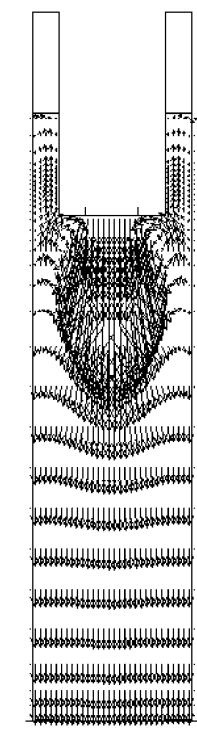

(b) $\mathrm{Vc}=1.5 \mathrm{~m} / \mathrm{min}$.

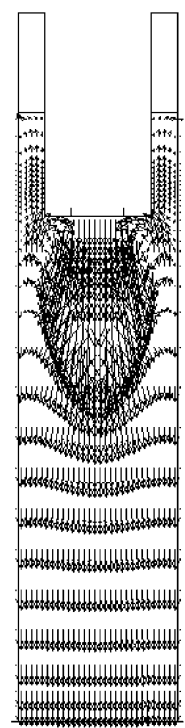

(c) $\mathrm{Vc}=1.7 \mathrm{~m} / \mathrm{min}$.

Fig. 6. The flow fields for the various submerged depths and withdrawal speeds.

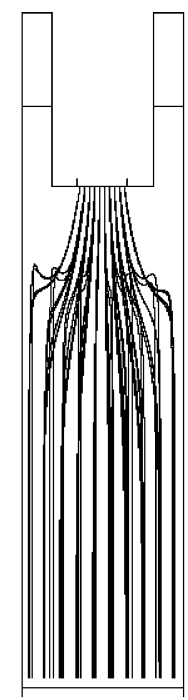

(a) Streaklines

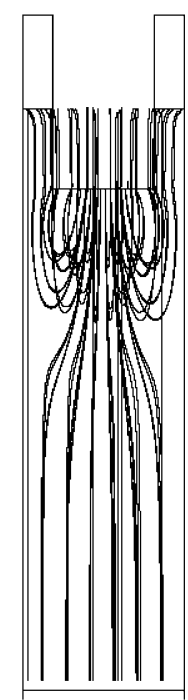

(b) $25 \mu \mathrm{m}$

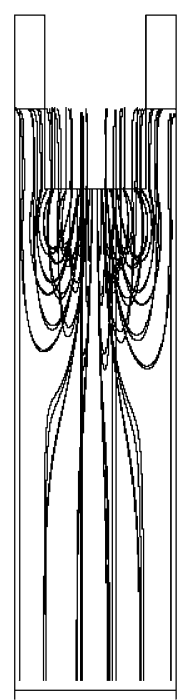

(c) $50 \mu \mathrm{m}$

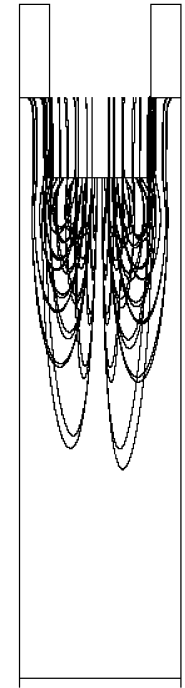

(d) $100 \mu \mathrm{m}$

Fig. 7. Streaklines and pathlines of inclusion particles with various sizes. (Design and operating condition: nozzle with single tapping hole, $V c=1.5 \mathrm{~m} / \mathrm{min}$., $D=80 \mathrm{~mm}$.)

to the total inclusions at the exit of the nozzle. In this study, 200 inclusions, which are evenly distributed on the nozzle exit, are used in the simulations. In Fig. 7, the pathlines of inclusion particles with various sizes at $V c=1.5 \mathrm{~m} / \mathrm{min}$ and $D=80 \mathrm{~mm}$ are shown. There are four particle sizes; 0,25 , 50 , and $100 \mu \mathrm{m}$. From the pathlines, the removal rate can be obtained. In Fig. 7(a), the particle size is $0 \mu \mathrm{m}$ and the pathlines are actually those of the fluid particles. Figures 7(b) and 7(c) show that the particles are partly trapped in the billet and partly removed by the top surface slag. Figure 7(d) shows that the inclusions are completely removed as their sizes reach $100 \mu \mathrm{m}$. It can be reasoned by the fact that particle velocity is calculated by Eq. (6). As Eq. (6) depicts, larger particle; larger $D_{\mathrm{p}}$, results in larger drag force, which acts on the particle in the opposite direction to the downward flow of molten steel. It means that larger particle is carried less deeply by the molten steel. In the mean time, a buoyant force, which acts upward on the particle, is always exerted on the particle. As a result, larger particle has a better chance to float to the top surface.

Table 3 lists the removal rates of inclusions of various sizes under various designs and operating conditions. For 
the same submerged depth, the inclusion removal rates for various casting speeds are slightly different. However, the influence of submerged depth on the inclusion removal rate is much more profound due to the fact that inclusion particle must travel a longer distance to float to the top surface slag.

\subsection{Nozzle with Two Tapping Holes Placed Horizon- tally}

Next, the design, where the submerged nozzle has two horizontal tapping holes, is examined with various submerged depths and casting speeds. Figure 8 shows the flow fields on the various sections of the casting mold with twotapping-hole nozzle under a casting speed of $1.5 \mathrm{~m} / \mathrm{min}$ and a submerged depth of $80 \mathrm{~mm}$. As shown in Figs. 8(a) and

Table 3. The inclusion removal rates for nozzle with single tapping hole under various operating conditions.

\begin{tabular}{|c|c|c|c|c|}
\hline $\begin{array}{c}\text { Size of } \\
\text { inclusion }\end{array}$ & $\begin{array}{c}\mathrm{V}_{\mathrm{c}}=1.5 \mathrm{~m} / \mathrm{min} . \\
\mathrm{D}=80 \mathrm{~mm}\end{array}$ & $\begin{array}{c}\mathrm{V}_{\mathrm{c}}=1.5 \mathrm{~m} / \mathrm{min} . \\
\mathrm{D}=100 \mathrm{~mm}\end{array}$ & $\begin{array}{c}\mathrm{V}_{\mathrm{c}}=1.7 \mathrm{~m} / \mathrm{min} . \\
\mathrm{D}=80 \mathrm{~mm}\end{array}$ & $\begin{array}{c}\mathrm{V}_{\mathrm{c}}=1.7 \mathrm{~m} / \mathrm{min} . \\
\mathrm{D}=100 \mathrm{~mm}\end{array}$ \\
\hline $25 \mu \mathrm{m}$ & $60 \%$ & $53.75 \%$ & $60 \%$ & $50 \%$ \\
\hline $50 \mu \mathrm{m}$ & $85 \%$ & $71.25 \%$ & $85 \%$ & $70 \%$ \\
\hline $100 \mu \mathrm{m}$ & $100 \%$ & $100 \%$ & $100 \%$ & $100 \%$ \\
\hline
\end{tabular}

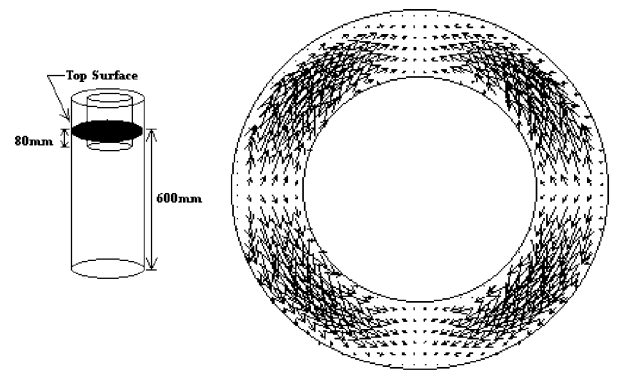

(a) X-Z section on the free surface

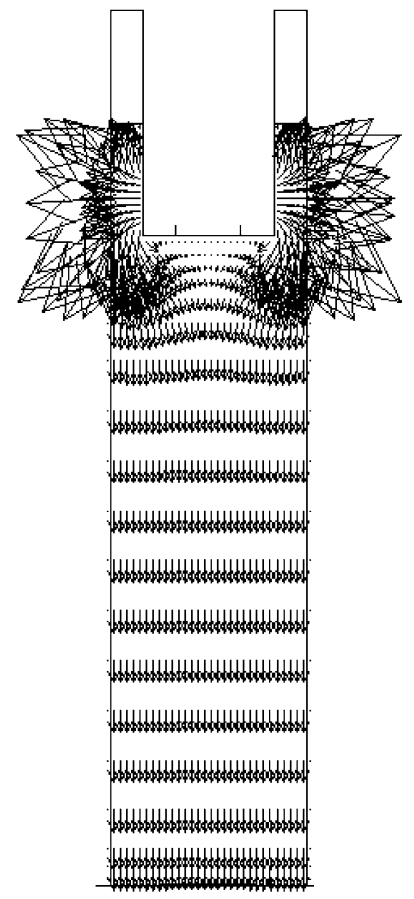

(c) X-Y section 8(c), molten steel flows out of the tapping holes and hits the casting mold. The molten steel spreads around after it strikes the mold wall. Some liquid rushes to the top surface and causes the surface to fluctuate. The cleanliness may get damaged due to the breakup of the top slag layer. The other melt streams meet underneath the nozzle and flow downward. Figure 8(d), which corresponds to the $Y-Z$ cross-section that is not aligned with the nozzle outlets, shows that the variation of velocity is not obvious.

Figures 9(a) through 9(d) show the velocity fields under two casting speeds $(1.5$ and $1.7 \mathrm{~m} / \mathrm{min})$ and two submerged depths $(D=80 \mathrm{~mm}$ and $100 \mathrm{~mm})$. These figures show when the casting speed is increased, the velocity is also increased as shown by the length of the velocity vector. When the submerged depth is equal to $80 \mathrm{~mm}$, substantial momentum of liquid is transported to the top surface as compared to the submerged depth of $100 \mathrm{~mm}$. The pathlines of inclusions with various sizes are again calculated. Figure 10 shows the pathlines of inclusions of various sizes at the casting speed of $1.5 \mathrm{~m} / \mathrm{min}$. and submerged depth of $80 \mathrm{~mm}$. The calculated pathlines for these cases are quite different from those for single tapping hole nozzle. Table 4 lists the inclusion removal rates for various operating conditions with nozzle of two tapping holes. As observed in the

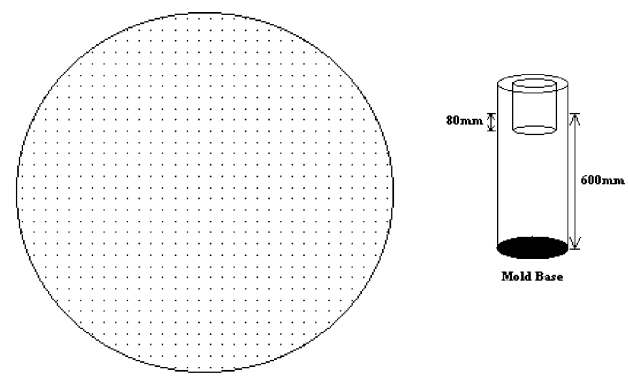

(b) X-Z section on the base of mold

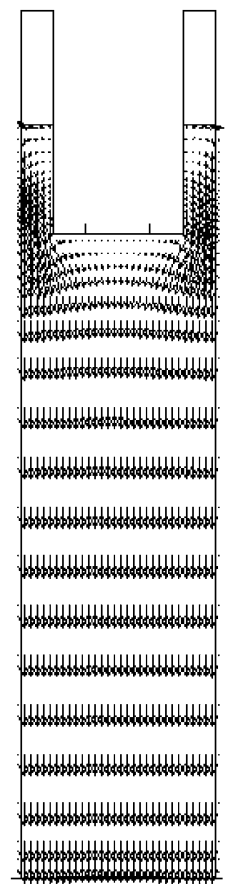

(d) Y-Z section

Fig. 8. Flow fields on various sections of the casting mold with two-tapping-hole nozzle under the casting speed of $1.5 \mathrm{~m} / \mathrm{min}$ and submerged depth of $80 \mathrm{~mm}$. 


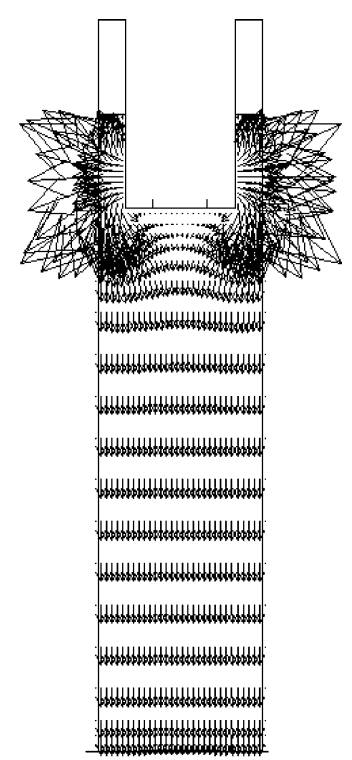

(a) $\mathrm{Vc}=1.5 \mathrm{~m} / \mathrm{min}$. $\mathrm{D}=80 \mathrm{~mm}$

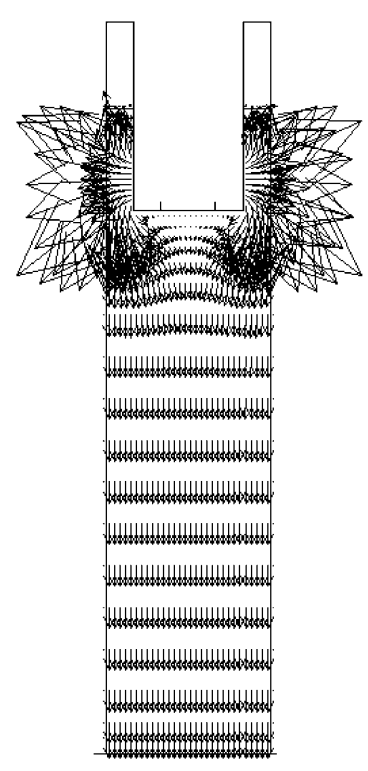

(b) $\mathrm{Vc}=1.7 \mathrm{~m} / \mathrm{min}$. $\mathrm{D}=80 \mathrm{~mm}$

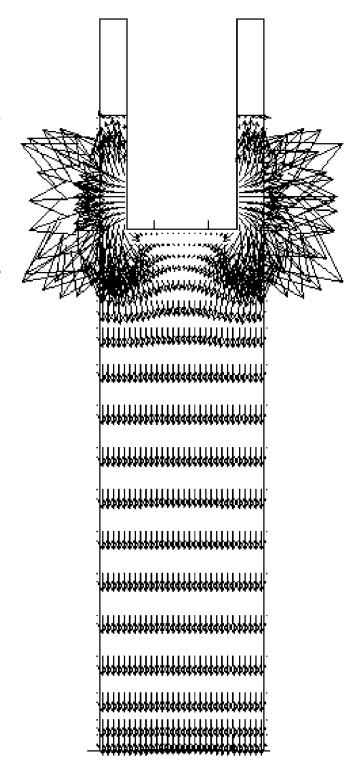

(c) $\mathrm{Vc}=1.5 \mathrm{~m} / \mathrm{min}$. $\mathrm{D}=100 \mathrm{~mm}$

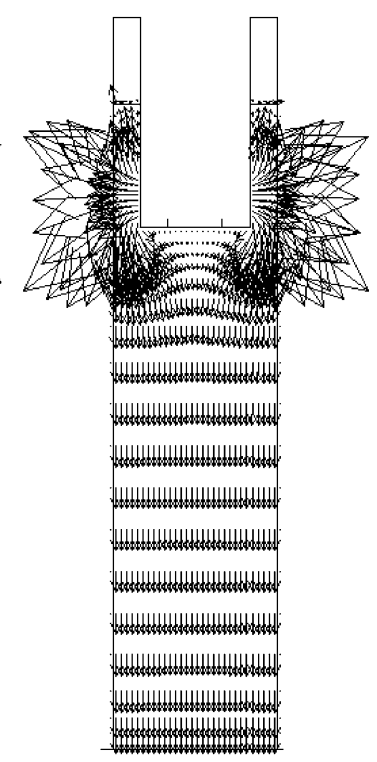

(d) $\mathrm{Vc}=1.7 \mathrm{~m} / \mathrm{min}$. $\mathrm{D}=100 \mathrm{~mm}$

Fig. 9. Velocity fields for the various operating conditions with nozzle of two tapping holes.

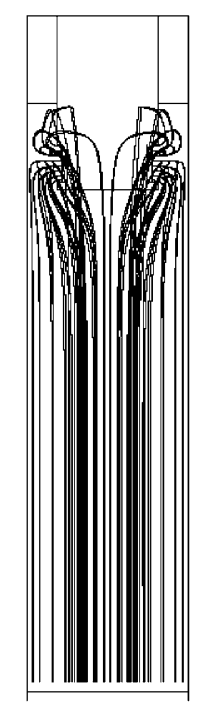

(a) Streaklines

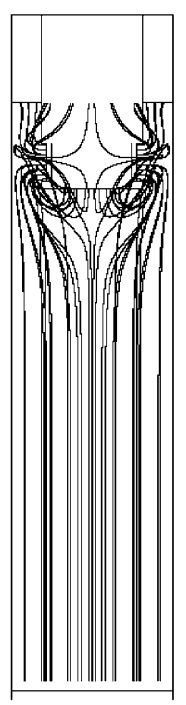

(b) $25 \mu \mathrm{m}$

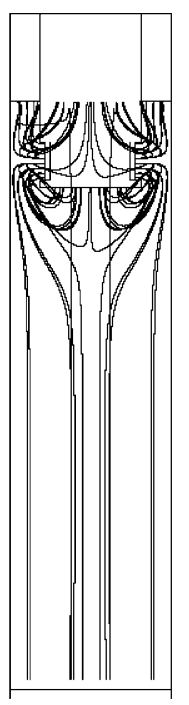

(c) $50 \mu \mathrm{m}$

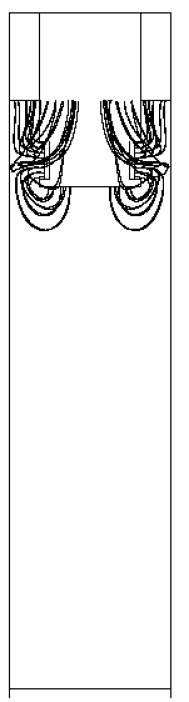

(d) $100 \mu \mathrm{m}$

Fig. 10. Streaklines and pathlines of the inclusions with various sizes. (Design and operating condition: two-tappingholes nozzle, $V c=1.5 \mathrm{~m} / \mathrm{min}, D=80 \mathrm{~mm}$.)

Table 4. The inclusion removal rates for nozzle with two horizontal tapping holes under various operating conditions.

\begin{tabular}{|c|c|c|c|c|}
\hline $\begin{array}{c}\text { Size of } \\
\text { inclusion }\end{array}$ & $\begin{array}{c}\mathrm{V}_{\mathrm{c}}=1.5 \mathrm{~m} / \mathrm{min} . \\
\mathrm{D}=80 \mathrm{~mm}\end{array}$ & $\begin{array}{c}\mathrm{V}_{\mathrm{c}}=1.5 \mathrm{~m} / \mathrm{min} . \\
\mathrm{D}=100 \mathrm{~mm}\end{array}$ & $\begin{array}{c}\mathrm{V}_{\mathrm{c}}=1.7 \mathrm{~m} / \mathrm{min} . \\
\mathrm{D}=80 \mathrm{~mm}\end{array}$ & $\begin{array}{c}\mathrm{V}_{\mathrm{c}}=1.7 \mathrm{~m} / \mathrm{min} . \\
\mathrm{D}=100 \mathrm{~mm}\end{array}$ \\
\hline $25 \mu \mathrm{m}$ & $60 \%$ & $55 \%$ & $60 \%$ & $55 \%$ \\
\hline $50 \mu \mathrm{m}$ & $85 \%$ & $67.5 \%$ & $84.75 \%$ & $70 \%$ \\
\hline $100 \mu \mathrm{m}$ & $100 \%$ & $100 \%$ & $100 \%$ & $100 \%$ \\
\hline
\end{tabular}

previous case, submerged depth of nozzle still has a much more profound effect on the inclusion removal than casting speed.

As previously speculated before this study was conducted, the casting mold with the nozzle of two horizontal tapping holes should have higher efficiency in removing the inclusion particles as the exit of the molten steel from the nozzle is closer to the top surface. However, the simulated results show that the efficiency in inclusion removal is not very different for the two nozzle designs. From the operation point of view, the nozzle with single tapping hole is simpler than that of two horizontal tapping holes. Thus, the nozzle of single tapping hole is more favorable.

\section{Summary}

In this study, a three-dimensional mathematical model based on the SOLA-SURF scheme with the incorporation of the partial-cell technique has been developed to simulate the flow field of molten steel and pathline of inclusion in a billet continuous casting mold, where billets of round cross section are cast. From the analyses, the following conclusions can be drawn.

(1) The partial cell technique, which can better fit the 
actual geometry of simulated system, can provide more accurate results from the simulations.

(2) As the submerged depth of nozzle is increased, the inclusion removal rate is decreased.

(3) Submerged depth of nozzle has a more profound effect on the inclusion removal rate than casting speed.

(4) The simulated results show that the efficiency in inclusion removal is not very different for the two nozzle designs. The nozzle of single tapping hole is thus more favorable from the operation point of view.

\section{Acknowledgment}

The authors wish to thank the Walsin Lihwa Speciality Steel Corporation for financially supporting this study.

\section{Nomenclature}

$A_{i}, A_{j}: \quad$ Area fraction in the $i$ - or $j$-direction

$A_{\mathrm{c}}:$ Volume fraction in a mesh

$A_{\text {inlet }}, A_{\text {outlet }}$ : The cross section area of the nozzle and CC mold $\left(\mathrm{m}^{2}\right)$

$U_{i}, U_{j}:$ Fluid velocity in the $i$ - or $j$-direction $(\mathrm{m} / \mathrm{s})$

$t:$ Time (s)

$X_{i}, X_{j}:$ The $i$ - or $j$-direction (m)

$g_{i}$ : Gravity in the $i$-direction $\left(\mathrm{m} / \mathrm{s}^{2}\right)$

$\rho_{1}, \rho_{\mathrm{p}}:$ Density of liquid or particle $\left(\mathrm{kg} / \mathrm{m}^{3}\right)$

$v_{\mathrm{e}}$ : Efficient dynamic viscosity $\left(\mathrm{m}^{2} / \mathrm{s}\right)$

$P: \quad$ Pressure $\left(\mathrm{kg} / \mathrm{m} \cdot \mathrm{s}^{2}\right)$

$K$ : Turbulence kinetic energy $\left(\mathrm{m}^{2} / \mathrm{s}^{2}\right)$

$\varepsilon$ : Dissipation rate of turbulence kinetic energy $\left(\mathrm{m}^{2} / \mathrm{s}^{2}\right)$

$v_{\mathrm{t}}$ : Turbulent dynamic viscosity $\left(\mathrm{m}^{2} / \mathrm{s}\right)$ $\mathrm{c}_{1}, \mathrm{c}_{2}, \mathrm{c}_{3}, \sigma_{k}, \sigma_{\varepsilon}: \quad$ Turbulence constants

$H$ : Height of liquid (m)

$U, V, W: \quad$ Velocity components in $X, Y$, and $Z$ direction $(\mathrm{m} / \mathrm{s})$

$U_{\mathrm{pi}}$ : Velocity of particle in the $i$-direction $(\mathrm{m} / \mathrm{s})$

Re: Reynolds number

$C_{\mathrm{A}}$ : Mass coefficient

$C_{\mathrm{d}}: \quad$ Drag coefficient

$D_{\mathrm{p}}: \quad$ Diameter of particle $(\mu \mathrm{m})$

$\mu_{1}$ : Molecular viscosity $(\mathrm{kg} / \mathrm{m} \cdot \mathrm{s})$

$V_{\text {inlet }}, V_{\text {outlet }}$ : Velocities in the nozzle outlet and CC mold outlet $(\mathrm{m} / \mathrm{s})$

$V_{\mathrm{r}}$ : Relative velocity between liquid and particle $(\mathrm{m} / \mathrm{s})$

$V c$ : Casting speed $(\mathrm{m} / \mathrm{s})$

$D$ : Submerged depth of nozzle $(\mathrm{mm})$

\section{REFERENCES}

1) S. K. Choudhary, D. Mazumdar and A. Ghosh: ISIJ Int., 33 (1993), 764.

2) X. Huang and B. G. Thomas: Metall. Trans. B, 24B (1993), 379

3) A. Imamura, A. Kusano and N. Moritama: Tetsu-to-Hagané, 78 (1992), 439.

4) B. G. Thomas, L. J. Mika and F. M. Najjar: Metall. Trans. B, 21B (1990), 387.

5) X. Huang, B. G. Thomas and F. M. Najjar: Metall. Trans. B, 23B (1992), 339

6) P. Flint: $73^{\text {rd }}$ Steelmaking Conf., ISS/AIME, Pittsburgh, (1990).

7) Y. F. Chen and W. S. Hwang: Trans. A. F. S, (1996), 197.

8) R. Clift, J. R. Grace and M. E. Weber: Bubbles, Drops, and Particles, Academic Press, London, (1978), 111. 